\title{
EVALUATE SOME NEW INBRED RICE AND MALE STERILE VARIETIES UNDER DUS AND VCU EXPERIMENTS
}

\author{
S.H. ABOU KHADRAH ${ }^{1}$, M.I. ABO YOUSSEF ${ }^{2}$, \\ E.M. HAFEZ ${ }^{1, *}$, A.A. REHAN ${ }^{2}$
}

*E-mail: emadhafez2014@gmail.com

Received: July 15, 2020. Revised: Oct. 05, 2020. Accepted: Oct. 10, 2020. Published online: Oct. 16, 2020

\begin{abstract}
The main objective of study are evaluated some new inbred rice and male sterile varieties under Distinct, Uniform and Stability (DUS) and Value of Cultivated and Used (VCU) Experiments. A number of seven rice varieties were used, Sakha 101, Sakha 102, Sakha 104, Giza 177, Giza 178, Giza 182 and Egyptian yasmine; moreover, GZ 10154 and GZ 8564-Sp 70, as well as EGMS and CMS1 as promising lines to evaluating by DUS and VCU. The data were recorded on morphological and yield characters. The results could be concluded that: regarding to qualitative characteristics (PQ and QL), from 24 PQ and QL characters, the nine rice varieties recorded the same score for 19 characters; moreover, the rice varieties Egyptian jasmine was dissimilar in the score No. 24, 39, and 60, that referred to this variety belong to Indica type, while the rice varieties Sakha 101 and Giza 178 were similar only in score no.11, which belong to Japonica and Indica japonica types, that
\end{abstract}

meaning these varieties were highly uniform and stability in qualitative characters than the other promising line GZ 10154. Regarding to quantities characteristics (QN), from 27 QN characters, nine rice varieties recorded the same score for 20 characters; moreover, the rice varieties Sakha 101, Sakha 102, Sakha 104, Giza 177, Giza 178, Giza 182, Egyptian yasmine and GZ 8564-Sp70 were similar in the score no. 1, 12, 23, 48, 49 and 50, while the promising line GZ 10154 was dissimilar in these scores during the two seasons, meaning that all these varieties were highly uniform and stability than the other promising, line GZ 10154. These results were conformed to VCU results, where the studied varieties recorded the highest grain yield/day. From these results could be concluded that all the varieties, except GZ 10154, accepted as a new rice release variety, but the promising line GZ 10154 required to more recurrent selection to increase their uniform, as well as CMS line was

\footnotetext{
${ }^{1}$ Agronomy Department, Faculty of Agriculture Kafrelsheikh University, Egypt

${ }^{2}$ Rice Research Section, Field Crop Research Institute, ARC, Giza, Egypt
} 


\section{S.H. ABOU KHADRAH, M.I. ABO YOUSSEF, E.M. HAFEZ, A.A. REHAN}

accepted could be evaluated under different conditions, but EGMS should be evaluated under heat stress conditions.

Keywords: DUS: Distinctness, Uniformity and Stability; VCU: Value for Cultivation and Used.

\section{INTRODUCTION}

Rice (Oryza sativa L.) is one of the most important cereal crops in all over the world. In Egypt it is one of the major cereal crops. The total cultivated area of rice crop about 0.858 million fed., produced about 3.12 million ton of paddy rice with an average of $3.64 \mathrm{t} /$ fed., which was considered one of the highest average yield in the world. This is a unique and model act, which gives equal importance to the farmers and breeders and treats them as partners in their efforts for sustainable food security (Patra, 2000; Hafez et al., 2019a). Thus, the process of variety identification includes several steps (Identification of a variety, Confirmation of the variety, Distinctness of the variety from all other in common knowledge, Purity of the variety and Characterization of the variety), which enumerates its full descriptors. For a future release of cultivars, it is important to know the correlation among genotypes, especially male sterile across the environments, the coefficients of determination the effects of genotype and the interactions with other effects, such as locations, years, seasons, etc. and the components of total phenotypic variance. In the VCU tests, inferences should be drawn on individual environments, medium environments and new environments outside the experimental network (Resende, 2007; Hafez and Abou El-Hassan, 2015). Therefore, the main objective is: using DUS and VCU testing to characterization some of rice varieties and two types of male sterile.

\section{MATERIALS AND METHODS}

This experiment was carried out at the experimental Farm of Sakha Agriculture Research Station, Kafr El Sheikh Governorate, Egypt, and some inbred rice were evaluated during two successive summer seasons of 2016 and 2017. The main objective was to test varieties and two types of male sterile by using Distinct, Uniform and Stability (DUS) and the Value of Cultivated and Used (VCU.)

A number of 7 rice varieties were used, Sakha 101, Sakha 102, Sakha 104, Giza 177, Giza 178, Giza 182 and Egyptian yasmine. Moreover (GZ.10154, GZ8564Sp70, CMS and EMS), as promising lines under releasing and evaluating by DUS and VCU tests under tow planting methods: the first one is drill method and was planted by machine for DUS and the second planting method is manual transplanting for VUC, during $15^{\text {th }}$ May for each of 2015, 2016 and 2017 seasons, respectively. The experimental design was a randomized complete block design with three replications; the culture practices were applied as recommended by RRTC (2014). The date was recorded according to UPOV (2004).

For DUS test "Quantitative characteristics" are those where the expression covers the full range of variation from one extreme to the other. The expression can be recorded on a onedimensional, continuous or discrete, linear 
scale. "Qualitative characteristics" are those that are expressed in discontinuous states (e.g. sex of plant: dioeciously female (1), dioeciously male (2), monoecious unisexual (3), monoecious hermaphrodite (4). These states are selfexplanatory and independently meaningful. In the case of "Pseudoqualitative Characteristics," the range of expression is at least partly continuous, but varies in more than one dimension [e.g. shape: ovate (1), elliptic (2), circular (3), obviate (4)] and cannot be adequately described by just defining two ends of a linear range.

For VCU test, the data were recorded on morphological and yield characters as research by SES 2014. All statistical analysis was performed using analysis of variance technique by means of "COSTAT" computer soft war package (Gomez and Gomez 1984).

\section{RESULTS AND DISCUSSION}

The results obtained from the present investigation in the three successive seasons of 2015, 2016 and 2017 are presented and discussed in two topics, as follows:

1) (DUS) Distinct, Uniform and Stability (DUS) tests under drill planting method;

2) Value of Cultivated and Used (VCU) of some rice varieties under transplanting methods.

To establish distinctiveness among rice cultivars, 51 characters have been used. Qualitative characters are considered as morphological markers in the identification of rice varieties, because they are less influenced by environmental changes.

\section{Regarding to qualitative}

characteristics (PQ and QL), as shown in (Tables 1 and 3), the nine rice varieties recorded the same score for 19 characters; moreover, the promising varieties under releasing were dissimilar in the testing no.1, 24, 39 , 46, and 60 , indicating to the variances in morphological characters, while the promising varieties Sakha 101 and Giza 178 were similar only in testing no.11, as well as promising lines GZ8564-Sp70 and Sakha 101 were similar in testing no. 39, that meaning the promising line GZ 8564Sp70 it's homozygous line during the two seasons. The Egyptian yasmin was dissimilar with studied varieties in the testing no. 39 and 60, but similar with Giza 182 in the testing no. 60, that meaning could be distinguish between Indica and Japonica type by these testing. For the male sterile, the CMS line was dissimilar with studied varieties in the testing no 20 and 39, while the EGMS line was similar to the studied varieties in the testing no. 20 and 39; that meaning could be evaluate the CMS line under different condition, but the EGMS line should be evaluate under heat stress conditions. These results were confirmed by Raut (2003), who concluded that characterization of variety is useful to identify and avoid duplication. 
Table 1 - Scaling test for PQ (pseudo-qualitative) and QL (qualitative) under DUS experiment, during 2015 and 2016 seasons

\begin{tabular}{|c|c|c|c|c|c|c|c|c|c|c|c|c|c|c|c|}
\hline \multirow{3}{*}{$\begin{array}{l}\begin{array}{c}\text { Scaling } \\
\text { test no. }\end{array} \\
\frac{2}{2}\end{array}$} & \multirow{3}{*}{$\begin{array}{l}\text { Traits } \\
\text { Basal leaf: sheath color }\end{array}$} & \multirow{2}{*}{\multicolumn{14}{|c|}{ 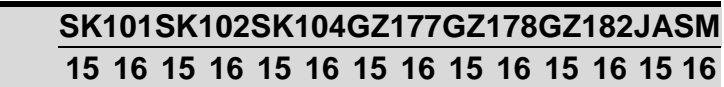 }} \\
\hline & & & & & & & & & & & & & & & \\
\hline & & PQ 1 & 1 & 1 & 1 & 1 & 1 & 1 & 1 & 1 & 1 & 1 & 1 & 1 & 1 \\
\hline 4 & Leaf: anthocyanin coloration & QL 1 & 1 & 1 & 1 & 1 & 1 & 1 & 1 & 1 & 1 & 1 & 1 & 1 & 1 \\
\hline 6 & $\begin{array}{l}\text { Leaf sheath: anthocyanin } \\
\text { coloration }\end{array}$ & QL 1 & 1 & 1 & 1 & 1 & 1 & 1 & 1 & 1 & 1 & 1 & 1 & 1 & 1 \\
\hline 9 & $\begin{array}{l}\text { Leaf: anthocyanin coloration } \\
\text { of auricles }\end{array}$ & QL 1 & 1 & 1 & 1 & 1 & 1 & 1 & 1 & 1 & 1 & 1 & 1 & 1 & 1 \\
\hline 10 & $\begin{array}{l}\text { Leaf: anthocyanin coloration } \\
\text { of collar }\end{array}$ & QL 1 & 1 & 1 & 1 & 1 & 1 & 1 & 1 & 1 & 1 & 1 & 1 & 1 & 1 \\
\hline 11 & Leaf: shape of ligules & PQ 2 & 2 & 3 & 3 & 3 & 3 & 3 & 3 & 2 & 2 & 3 & 3 & 3 & 3 \\
\hline 12 & Leaf: color of ligules' & PQ 1 & 1 & 1 & 1 & 1 & 1 & 1 & 1 & 1 & 1 & 1 & 1 & 1 & 1 \\
\hline 17 & Culm: habit & PQ 1 & 1 & 1 & 1 & 1 & 1 & 1 & 1 & 1 & 1 & 1 & 1 & 1 & 1 \\
\hline 20 & Male sterility & PQ 1 & 1 & 1 & 1 & 1 & 1 & 1 & 1 & 1 & 1 & 1 & 1 & 1 & 1 \\
\hline 21 & $\begin{array}{l}\text { Lemma: anthocyanin } \\
\text { coloration of keel (early } \\
\text { observation) }\end{array}$ & QN 1 & 1 & 1 & 1 & 1 & 1 & 1 & 1 & 1 & 1 & 1 & 1 & 1 & 1 \\
\hline 22 & $\begin{array}{l}\text { Lemma: anthocyanin } \\
\text { coloration of area below } \\
\text { apex }\end{array}$ & QN 1 & 1 & 1 & 1 & 1 & 1 & 1 & 1 & 1 & 1 & 1 & 1 & 1 & 1 \\
\hline 24 & Spikelet: color of stigma & PQ 1 & 1 & 3 & 3 & 1 & 1 & 1 & 1 & 1 & 1 & 1 & 1 & 3 & 3 \\
\hline 27 & $\begin{array}{l}\text { Stem } \\
\text { color }\end{array}$ & QL 1 & 1 & 1 & 1 & 1 & 1 & 1 & 1 & 1 & 1 & 1 & 1 & 1 & 1 \\
\hline 29 & $\begin{array}{l}\text { Stem: anthocyanin } \\
\text { coloration of internodes }\end{array}$ & QL 1 & 1 & 1 & 1 & 1 & 1 & 1 & 1 & 1 & 1 & 1 & 1 & 1 & 1 \\
\hline 32 & Panicle: awns & QL 1 & 1 & 1 & 1 & 1 & 1 & 1 & 1 & 1 & 1 & 1 & 1 & 1 & 1 \\
\hline 37 & $\begin{array}{l}\text { Spikelet: color of tip of } \\
\text { lemma }\end{array}$ & PQ 1 & 1 & 1 & 1 & 1 & 1 & 1 & 1 & 1 & 1 & 1 & 1 & 1 & 1 \\
\hline 39 & $\begin{array}{l}\text { Panicle: attitude in relation } \\
\text { to stem }\end{array}$ & PQ 2 & 2 & 2 & 2 & 2 & 2 & 2 & 2 & 2 & 2 & 2 & 2 & 3 & 3 \\
\hline 40 & $\begin{array}{l}\text { Panicle: presence of } \\
\text { secondary branching }\end{array}$ & QL 9 & 9 & 9 & 9 & 9 & 9 & 9 & 9 & 9 & 9 & 9 & 9 & 9 & 9 \\
\hline 41 & $\begin{array}{l}\text { Panicle: type of secondary } \\
\text { branching }\end{array}$ & PQ 1 & 1 & 1 & 1 & 1 & 1 & 1 & 1 & 1 & 1 & 1 & 1 & 1 & 1 \\
\hline 46 & Lemma: color & PQ 2 & 2 & 2 & 2 & 2 & 2 & 2 & 2 & 2 & 2 & 2 & 2 & 2 & 2 \\
\hline 47 & Lemma: ornamentation & PQ 1 & 1 & 1 & 1 & 1 & 1 & 1 & 1 & 1 & 1 & 1 & 1 & 1 & 1 \\
\hline 52 & Glume: color & PQ 2 & 2 & 2 & 2 & 2 & 2 & 2 & 2 & 2 & 2 & 2 & 2 & 2 & 2 \\
\hline 60 & $\begin{array}{l}\text { Decorticated grain: shape } \\
\text { (in lateral view) }\end{array}$ & PQ 3 & 3 & 4 & 4 & 4 & 4 & 4 & 4 & 4 & 4 & 5 & 5 & 5 & 5 \\
\hline 61 & Decorticated grain: color & PQ 1 & 1 & 1 & 1 & 1 & 1 & 1 & 1 & 1 & 1 & 1 & 1 & & 1 \\
\hline
\end{tabular}

Qualitative traits being more stable over generations reveled that meet the continuously expanding needs of varietals improvement, the 
assemblage, evaluation, preservation and characterization of the entire existing genotypes are essential to more rewarding breeding efforts. Also, Shobha et al. (2004) reported that among the qualitative trait, 46 (22 essential and 24 additional) visually assessed characteristics were observed, according to the National Test Guidelines for DUS test in rice, which was developed by Directorate of Rice Research Rajendranagar, Hyderabad (Hafez and Seleiman, 2017)

Regarding to quantitive characteristics (QN) (Tables 2 and 4), from 27 QN characters, the nine rice genotypes recorded the same score for 20 characters; moreover, the promising varieties Sakha 101, Sakha 102, Sakha 104, Giza 177, Giza 178, Giza 182, Egyptian yasmin, GZ8564Sp70 and GZ10154 were dissimilar in the testing No. 3, 13, 16, 19 and 44, while the promising line GZ10154 was dissimilar in the testing No.3,8,13,19 36,42,43,44 and 53, during two season, that meaning the promising line GZ 8564-SP70 was highly uniform and stability in quantitive characteristics than the other promising line GZ10154. For the testing No. 19 and 44, as shown in Tables 2 and 4, the early maturing varieties, Sakha 102, Giza 177 and Giza 182, recorded the score no. 3, while the medium maturing varieties Sakha 104 and Giza 178 recorded the score no. 5, but the medium late maturing varieties Sakha 101, GZ 8564-Sp70 and GZ10154 recorded the score no. 7. Finally, the variety Egyptian yasmin recorded the score no. 9, as late maturing variety. On the other side, the CMS line record the score no. 7 as medium late maturing variety, while the EGMS line recorded the score no. 5 as medium maturing variety. The results were confirmed by those obtained from VCU experiment.

For any variety to be capable of protection it must first be clearly defined. Only after a variety has been defined can it be finally examined for fulfillment of DUS criteria required for protection. All acts of the (UPOV) convention have established that a variety is defined by its characteristics and that those characteristics are therefore the basis on which a variety can be examined for DUS. In addition to their use in defining a variety, characteristics are the basis for examining distinctness, uniformity and stability (Hafez et al., 2014; Kheir et al., 2019; Seleiman et al., 2019).

The material to be submitted for the examination of DUS should be representative of the candidate variety. In the case of varieties with a particular cycle of propagation, such as hybrid and synthetic varieties, this means that the material tested should include the final stage in the cycle of propagation. The plant material submitted for examination should be visibly healthy, not lacking in vigor or affected by any important pests or diseases and, in the case of seed, should have sufficient germination capacity for the conduct of a satisfactory examination (Hafez and Kobata, 2012). 


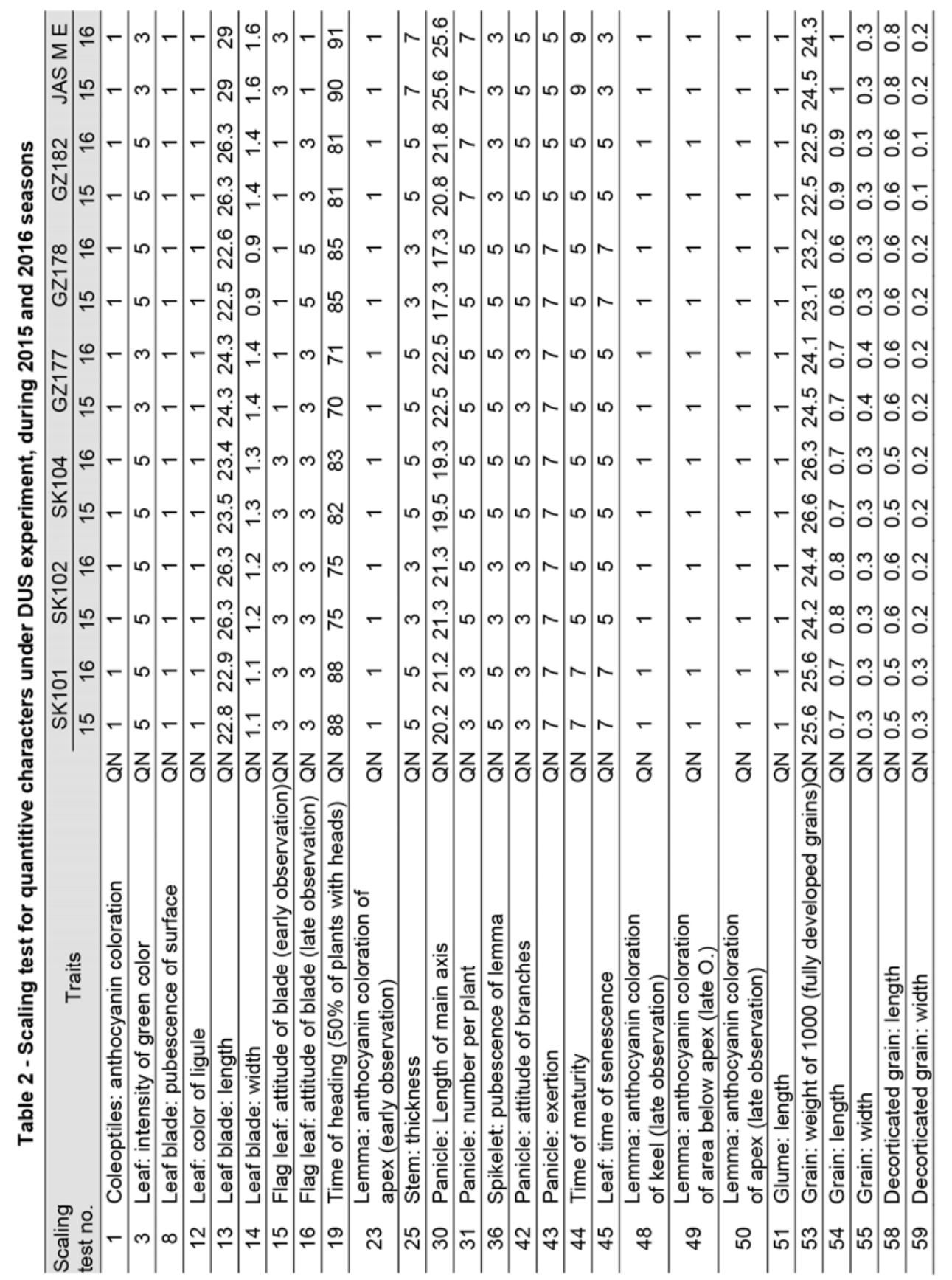


NEW INBRED RICE AND MALE STERILE VARIETIES UNDER DUS AND VCU EXPERIMENTS

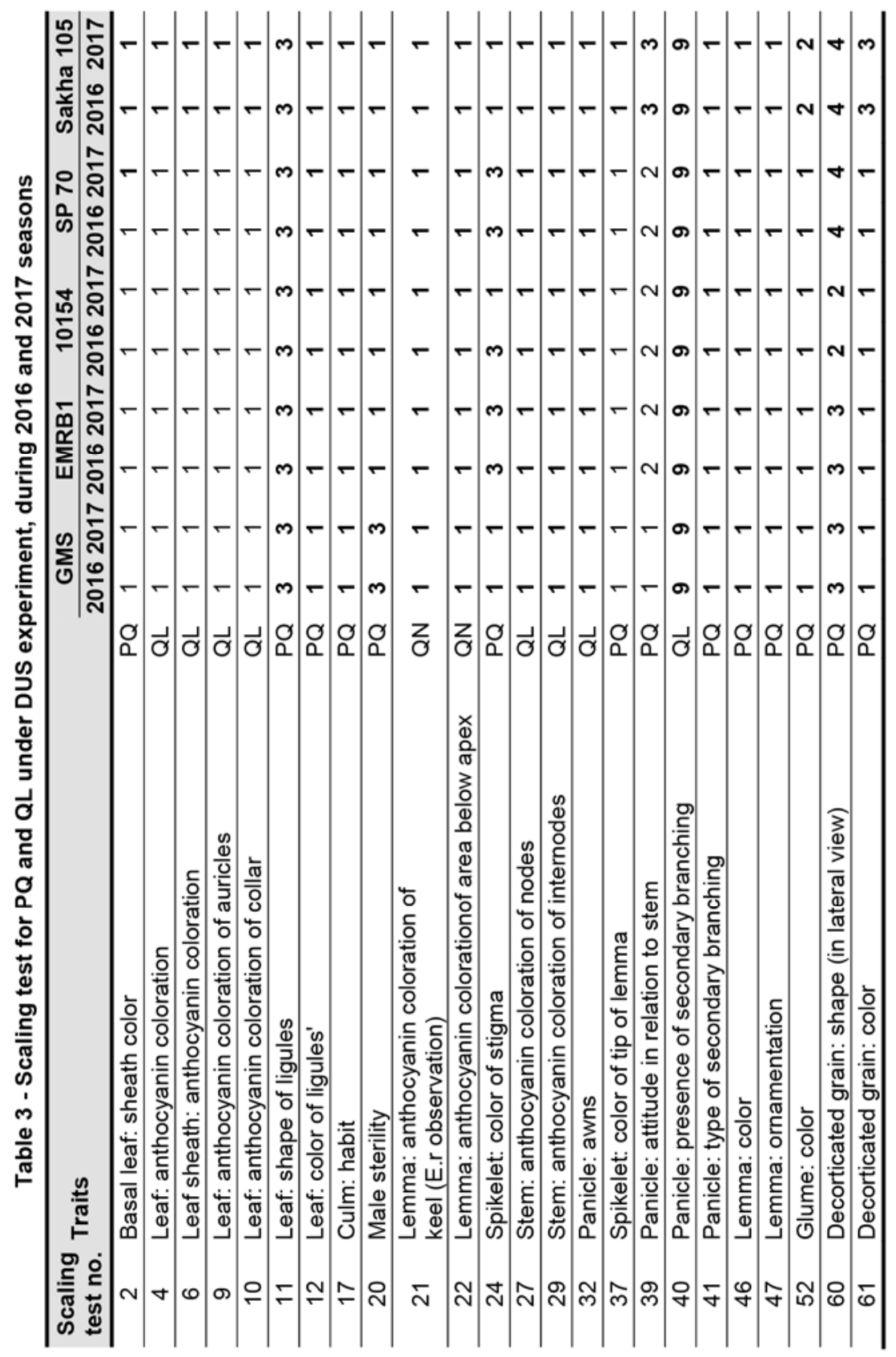




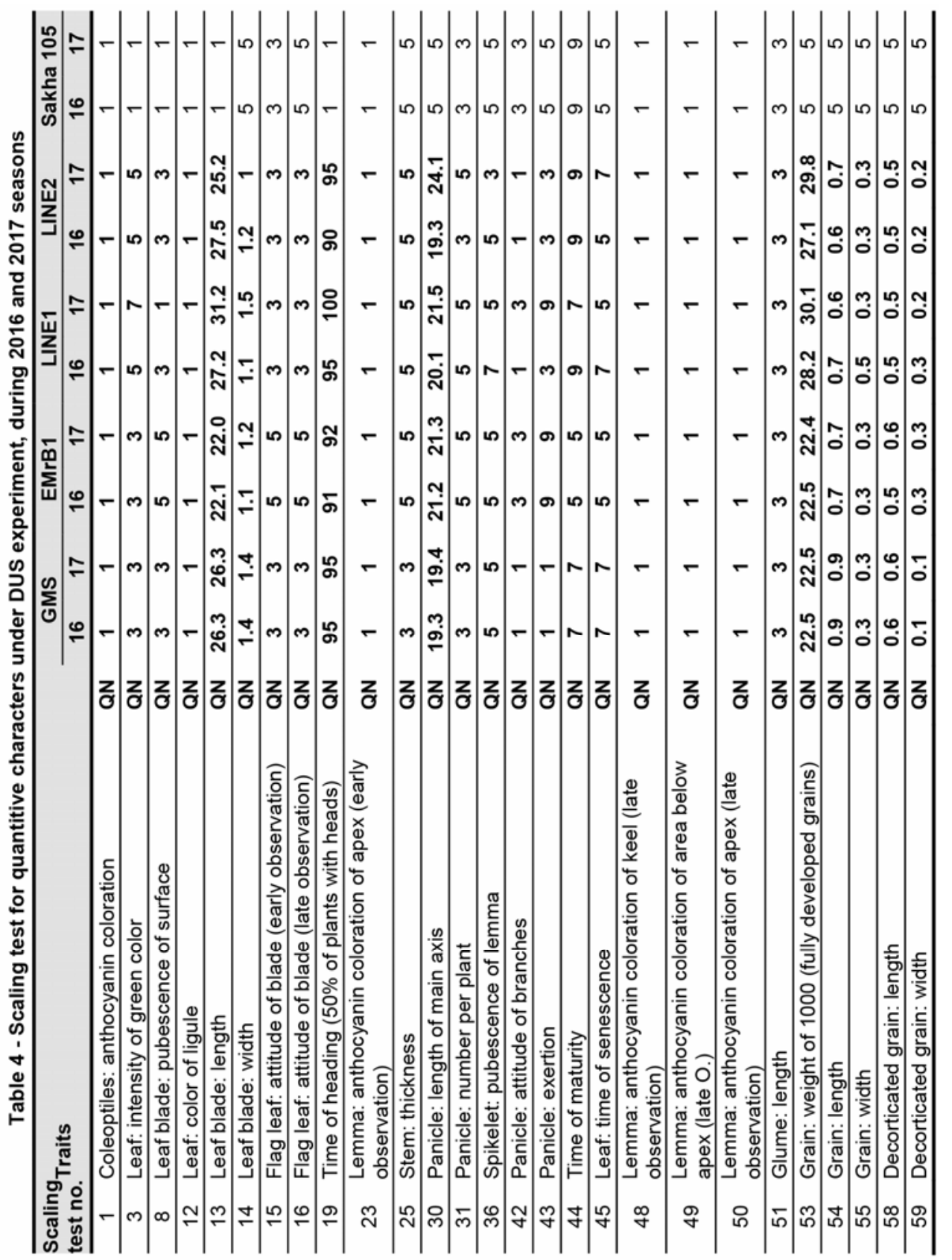


The expression of a characteristic or several characteristics of a variety may be affected by factors, such as pests and disease, chemical treatment (e.g. growth retardants or pesticides), effects of tissue culture, different rootstocks, scions taken from different growth phases of a tree, etc. In some cases (e.g. disease resistance), reaction to certain factors is intentionally used as characteristic in the DUS examination. However, where the factor is not intended for DUS examination, it is important that it's influence does not distort the DUS examination. Ramalingam et al. (1992), Gharib et al. (2016) and Hafez and Abdelaal (2015) found that the mode of gene action of the two restorer genes for CMS - WA varied with one of the two genes having stronger action than the other. Certain crosses should dominant epistasis, while, other should dominance.

For the EGMS lines, Virmani et al., 2003 and Hafez et al. (2018) mentioned that the EGMS is composed of two major types: photo period sensitive genic male sterility (PGMS), which is responsive to variations in day length, and thermo sensitive genic male sterility (TGMS), which is caused temperature.

To enable the appropriate use of characteristics in DUS testing, it's important to understand the different ways in which characteristics can be expressed. The following section identifies the different types of expression and considers their application in DUS testing (Hafez and Farig, 2019).

\section{Evaluating the materials under VCU experiment}

The planting method play importing role in gene (s) expression for rice plant, where the rice growth rate, tilliring ability, plant height, panicle length, days to heading, days to maturity and grain yield/ hill were highly affected by planting method, because the transplanting method enhancement the growth rate, then recording the highest values for most of the studied characters under the VCU experiment, compared to drill seeding method for the DUS experiment. The same results were obtained by Laary et al. (2012); Hafez and Gharib (2016); Hafez et al. (2019b). They mentioned that, among examined planting methods, the most consistent planting method and best in almost all examined parameters under individual years was the seedling transplanting method, followed by direct seed dibbling method.

In Table 5, the gene(s) expression for rice plant were highly affected by planting methods, especially for DUS test, where the transplanting method recorded the desirable values for the most studied characters; moreover, highly phenotype variance among the rice varieties were recorded, especial for no. of tillers/ hill, plant height, panicle length and grain yield (g/day). The results in Table 6 showed the highly variance within the grain yield for the rice varieties, compared to the other rice variety; moreover, all the varieties recorded more than $9.50(\mathrm{t} / \mathrm{ha})$, during both seasons (Hafez and Geries, 2018). 

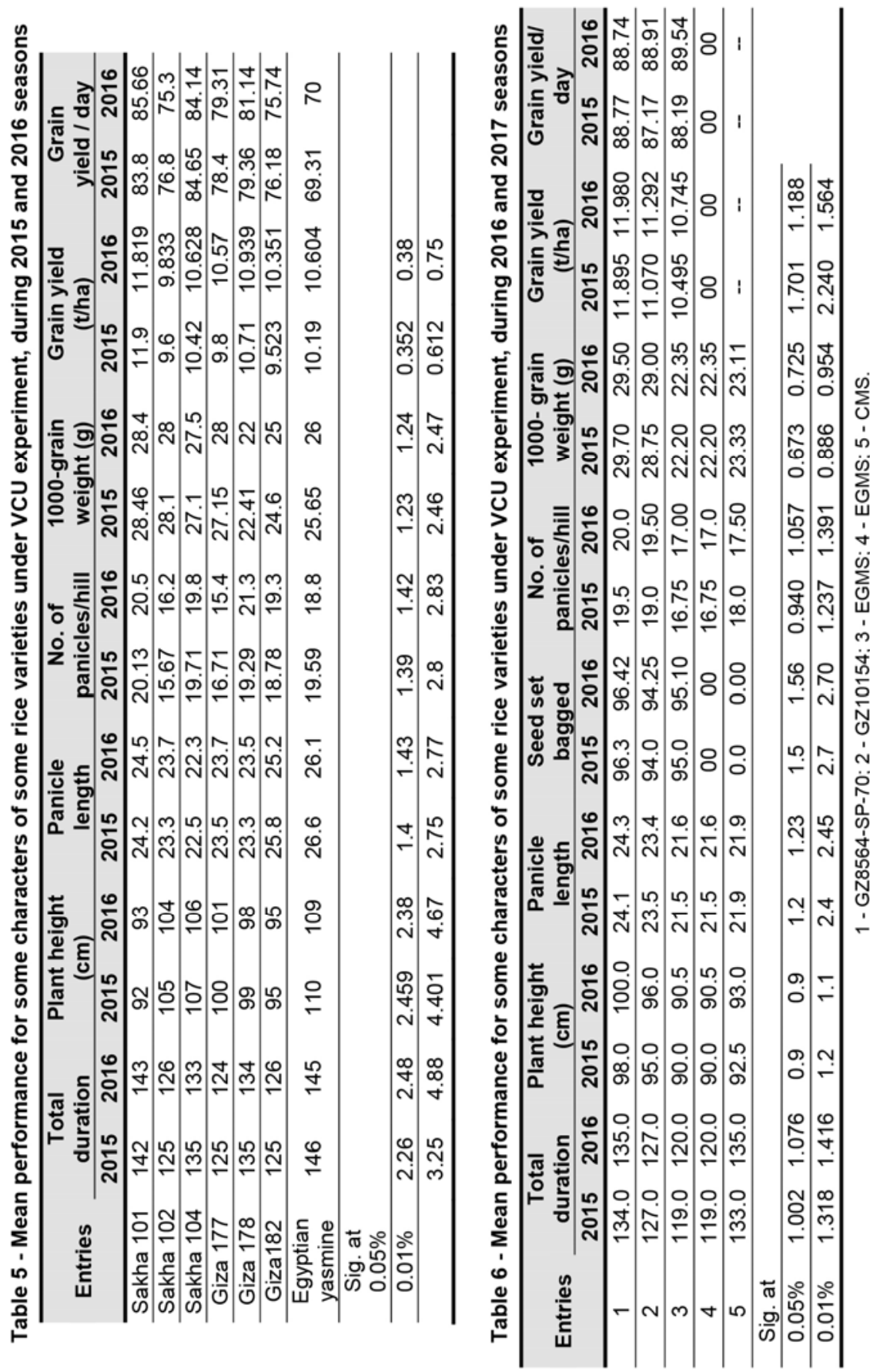
That means the promising line GZ 10154 had the lowest gain yield (t/ha), compared to the promising line GZ 8564-Sp70, which recorded the highest grain yield (g/day). From these results could be concluded that the line GZ 8564-Sp70 and the seven cultivated varieties were accepted as a new rice release varieties, as well as the CMS line as a new female line, while the promising line GZ 10154 required to more recurrent selection to increase their uniformity and stabile and EGMS line recorded to evaluate under high temperature condition (Hafez and Badawy 2018).

\section{CONCLUSIONS}

Regarding to quantities characteristics (QN), from $27 \mathrm{QN}$ characters, the nine rice varieties recorded the same score for 20 characters; moreover, the rice varieties Sakha 101, Sakha 102, Sakha 104, Giza 177, Giza 178, Giza 182, Egyptian Yasmine and GZ 8564-Sp70 were similar in the score no. $1,12,23,48,49$ and 50 , while the promising line GZ 10154 was dissimilar in these scores during the two seasons, meaning that all these varieties were highly uniform and stability than the other promising, line GZ 10154. These results were conformed to VCU results, where the studied varieties recorded the highest grain yield/day. From these results could be concluded that all the varieties, except GZ 10154, was accepted as a new rice release variety, but the promising line GZ 10154 required to more recurrent selection to increase their uniform, as well as CMS line was accepted and could be evaluated under different conditions, but EGMS should be evaluated under heat stress conditions.

\section{REFERENCES}

Gharib, H., Hafez, E. \& El Sabagh, A. (2016). Optimized potential of utilization efficiency and productivity in wheat by integrated chemical nitrogen fertilization and stimulative compounds. Cercet.Agron. in Moldova, 49(2): 5-20, DOI: 10.1515/ cerce-2016-0011

Gomez, K.A. \& Gomez, A.A. (1984). Statistical procedures for agricultural research. $2^{\text {nd }}$ Edition, John Wiley and Sons, Inc. New York.

Hafez, E.M. \& Kobata, T. (2012). The effect of different nitrogen sources from urea and ammonium sulfate on the spikelet number in Egyptian spring wheat cultivars on well watered pot soils. Plant Prod. Sci., 15(4): 332-338.

Hafez, E.M., Ragab, A.Y. \& Kobata, T. (2014). Water-use efficiency and ammonium- $\mathrm{N}$ source applied of wheat under irrigated and desiccated conditions. Int.J. Plant Soil Sci., 3(10): 1302-1316, DOI: 10. 9734/IJPSS/2014/9075

Hafez, E. \& Abou El-Hassan, W.H. (2015). Nitrogen and water utilization efficiency of barley subjected to desiccated conditions in moderately salt-affected soil. Egypt.J.Agron., 37(2): 231-249, DOI: 10.21608/ agro.2015.203

Hafez, E. \& Abdelaal, K.A.A. (2015). Impact of nitrogen fertilization levels on morphophysiological characters and yield quality of some maize hybrids (Zea mays L.). Egypt.J. Agron., 37(1): 35-48, DOI:10.21608/ agro.2015.62 


\section{S.H. ABOU KHADRAH, M.I. ABO YOUSSEF, E.M. HAFEZ, A.A. REHAN}

Hafez, E.M. \& Gharib, H.S. (2016). Effect of exogenous application of ascorbic acid on physiological and biochemical characteristics of wheat under water stress. Int.J. Plant Prod., 10(4): 579596, DOI: 10.22069/ijpp.2016.3051

Hafez, E.M. \& Seleiman, M.F. (2017). Response of barley quality traits, yield and antioxidant enzymes to water-stress and chemical inducers. Int.J Plant Prod., 11(4): 477-490, DOI: $10.22069 /$ JJPP.2017.3712

Hafez, E. \& Badawy, Sh. (2018). Effect of bio fertilizers and inorganic fertilizers on growth, productivity and quality of bread wheat cultivars. Cercet.Agron. in Moldova, 51(4): 1-16, DOI: 10.24 78/cerce-2018-0031

Hafez, E., El-Gammaal, A. \& Rashwan, E. (2018). Pivotal impact of sources and rates of nitrogen fertilizers on yield, nitrogen use efficiency in bread wheat cultivars. Azarian J.Agric., 5(5): 142-150.

Hafez, E. \& Geries, L. (2018). Effect of nitrogen fertilization and biostimulative compounds on onion productivity. Cercet.Agron. in Moldova, 51(1): 76-90, DOI: 10.24 78/cerce-2018-0007

Hafez, E.M., Alsohim, A.S., Farig, M., Omara, A.E.D., Rashwan, E. \& Kamara, M.M. (2019a). Synergistic effect of biochar and plant growth promoting rhizobacteria on alleviation of water deficit in rice plants under salt-affected soil. Agron., 9(12): 847, DOI: 10.3390/ agronomy 9120847

Hafez, E. \& Farig, M. (2019). Efficacy of salicylic acid as a cofactor for ameliorating effects of water stress and enhancing wheat yield and water use efficiency in saline soil. Int.J. Plant Prod., 13(163-176), DOI: 10.1007/s42106-019-00036-w

Hafez, E., Omara, A.E.D. \& Ahmed, A. (2019b). The coupling effects of plant growth promoting rhizobacteria and salicylic acid on physiological modifications, yield traits, and productivity of wheat under water deficient conditions. Agron., 9(9): 524,DOI:10.3390/agronomy9090524

Kheir, A.S., Abouelsoud, H.M., Hafez, E.M. \& Ali, O.A.M. (2019). Integrated effect of nano-Zn, nano$\mathrm{Si}$, and drainage using crop strawfilled ditches on saline sodic soil properties and rice productivity. Arab.J.Geosci., 12(15) 471, DOI:10. 1007/s12517-019-4653-0

Laary J.K., Dogbe, W., Boamah, P.O. \& Agawini, J. (2012). Evaluation of planting methods for growth and yield of "digang" rice (Oryza sativa L.) under upland condition of Bawku, Upper East Region, Ghana, ARPN, J.Agric.Biol.Sci., 7(10): 814-819.

Patra, B.C. (2000). Collection and characterization of rice genetic resources from Keonjhar district of Orissa. Oryza, 37(4): 324-326.

Ramalingam, J., Nadarajan, N., Rangasamy, P. \& Vanniarajan, C. (1992). Genetic analysis of fertility restoration in hybrid rice (Oryza sativa L.). Ann.Agric.Res., 13(3): 221-223.

Raut, V.M. (2003). Qualitative genetics of soyabean - a review. Soybean Res., 1: 1-28.

RRTC (2014). Rice research and training center, Annual report agron. Sakha, Kafr El-sheikh, Egypt.

Seleiman, M.F., Refay, Y., Al-Suhaibani, N., Al-Ashkar, I., El-Hendawy, S. \& Hafez, E.M. (2019). Integrative effects of rice-straw biochar and silicon on oil and Seed Quality, Yield and Physiological Traits of Helianthus annuus L. grown under water deficit stress. Agron. 9(10): 637, DOI: 10. 3390/agronomy91006 37

UPOV. (2004). International union for the protection of new varieties of plants.TG/1/3 Geneva.

Virmani, S.S., Vitaktamath, B.C., Casal, G.L., Toledo, R.S., Lopez M.T. \& Manalo, J.D. (1997). Hybrid rice breeding manual. Int. Rice Res.Inst. (IRRI), Los Baños, Laguna, Philippines, $151 \mathrm{p}$. 